\title{
Benefit Estimates for Landscape Improvements: Sequential Bayesian Design and Respondents' Rationality in a Choice Experiment
}

\author{
Riccardo Scarpa, Danny Campbell, and W. George Hutchinson
}

\begin{abstract}
A multi-attribute, stated-preference approach is used to value low and high impact actions on four major landscape components addressed by the Rural Environment Protection Scheme in Ireland. Several methodological issues are addressed: the use of prior beliefs on the relative magnitudes of parameters, standardized description of different levels of landscape improvements via image manipulation software, adoption of efficiency-increasing sequential experimental design, and sensitivity of benefit estimates to inclusion of responses from "irrational" respondents. Results suggest that Bayesian design updating delivers significant efficiency gains without loss in respondent efficiency, and estimates are upward-biased when irrational respondents are included. (JEL Q24, Q51)
\end{abstract}

\section{INTRODUCTION}

After more than fifty years of European Union (EU) agricultural policies designed to support farm incomes via farm commodity prices, there has been a significant shift in emphasis to area-based payments and payments for the supply of environmental goods, or "green payments." Such agrienvironmental schemes have become an important component within the Common Agricultural Policy (CAP). In particular, the Rural Environment Protection (REP) Scheme was introduced in Ireland in 1994, and was designed to pay farmers for carrying out their farming activities in an environmentally friendly manner and to improve the broadly defined rural environment, and the rural landscape.

By the end of 2004 , over $€ 1.5$ billion had been paid to Irish farmers under the REP

Land Economics • November 2007 • 83 (4): 617-634 ISSN 0023-7639; E-ISSN 1543-8325

(C) 2007 by the Board of Regents of the University of Wisconsin System
Scheme (henceforth the Scheme). Assessing whether the Scheme has offered value for money requires an examination of both its costs and benefits. While its financial costs are readily available, calculating the benefits is a more problematic and delicate matter, as evidenced by Randall (2002). Aside from the financial benefits farmers derive from participation, the Scheme offers a range of benefits to society (Mannion, Gorman, and Kinsella 2001; Gorman et al. 2001). Some of these include the enhanced value of rural landscape aesthetics, recreation amenities, improved water quality, wildlife preservation, and the maintenance of historical and archaeological features. Moreover, since no studies have sought to estimate these benefits, very little is known about their extent and magnitude (DAF 1999). A number of studies have examined the non-market benefits of agri-environmental schemes (Cooper and Keim 1996; Cooper 1997; Stewart, Hanley and Simpson 1997; Hellerstein et al. 2002; Cooper and Signorello forthcoming). Agri-environmental policy in Ireland is of interest in that it is unique in the EU as it is available to all farmers throughout the country (Emerson and Gillmor 1999). The policy objective of this study was to estimate willingness to pay (WTP) for rural landscape improvement measures within the Scheme.

Landscape conservation and improvement is currently one of the priorities of

The authors are, respectively, professor, Department of Economics, University of Waikato, Hamilton, New Zealand, research fellow, and professor, Gibson Institute for Land, Food and Environment, Queen's University, Belfast. This work was supported by funding from the Irish Department of Agriculture and Food under the Research Stimulus Fund and Teagasc under the Walsh Fellowship Scheme. The opinions expressed are those of the authors and need not reflect the Funders' positions. 
the revised CAP and the vision of a multifunctional agriculture it intends to promote. For a long time landscape evaluation has been the privileged domain of planners (Angileri and Toccolini 1993) and system modelers (Anderson 1981; Elefthriadis and Tsalikidis 1990; Björklund, Limburg and Rydberg 1999; Coiner, Wu, and Polasky 2001). More recently the issue of benefit estimation from landscapes has attracted the interest of economists who produced a number of theoretical (Brunstad, Ivar, and Erling 1999) and applied non-market valuation studies using contingent valuation (Willis and Garrod 1993, 1997; Pruckner 1995; Bullock and Kay 1997), multiattribute, stated-preference (Morrison et al. 2002; González and León 2003; Atkinson, Day, and Mourato 2004), travel cost (Fleischer and Tsur 2000), and hedonic methods (Geoghegan, Wainger, and Bockstael 1997; Boyle and Kiel 2001; Bastian et al. 2002).

The policy measures of the Scheme contribute to various rural landscape attributes, and hence a multi-attribute valuation approach is warranted. At the same time, the public good and non-market nature of the rural landscape favor the use of a statedpreference methodology employed for the estimation of existence benefits. This poses a number of methodological issues, yet to be satisfactorily addressed in the literature, which we took on as objectives of this empirical study. In particular, a first objective was the development of a survey instrument centered around digital images selected to represent what the Scheme implied in terms of specific policy actions on four distinct landscape features: Mountain Land (ML), Stonewalls (S), Farmyard Tidiness (FT) and Cultural Heritage $(\mathrm{CH})$. Image selection was approached by extensive farm surveying by professional rural landscape architects. Given the national scope of this study, and like in many similar stated preference studies relying on expensive survey instruments, the achievement of sufficiently accurate estimates at a manageable sample size was an important objective. Hence, efficiency gains were sought and achieved by adopting for the first time in the public good valuation literature, a Bayesian experimental design using the algorithm proposed by Sándor and Wedel (2001) with a variant that involved sequential updating, as suggested by Ferrini and Scarpa (2007). A further objective of this research was to explore the sensitivity of WTP estimates to responses from "irrational" individuals. These were identified by means of a protocol that selected respondents who made either inconsistent or irrational choices in their panel of discrete responses. Results from previous research (Johnson and Matthews 2001; Foster and Mourato 2002; San Miguel, Ryan, and Amaya-Amaya 2005) led to suggestions that identification of irrational respondents is desirable to test sensitivity of WTP estimates to violations of economic theory. Our analysis is conducted differently from previous analysis; we use mixed-logit panel estimators, with distributional assumptions that account for the positive nature of improvements, and focus on the distribution of implied individualspecific WTP estimates. The results provide evidence of a high sensitivity of implied distributions of individual-specific WTP estimates to the inclusion of "irrational" respondents in the sample, and suggest that previous results - which were based on uncorrelated taste parameter specifications and found such differences to be insignificant - should be re-examined.

The remainder of the article is organized as follows. In Section 2 we provide a brief background on the Scheme, while in Section 3 we explain the design of the experiment, with focus on both experimental design and the protocol for the preference consistency tests of responses. In Section 4 we describe the analytical approach used in the data analysis. In Section 5 we describe and discuss the relevant results from the analysis and in Section 6 we draw our conclusions.

\section{THE RURAL ENVIRONMENT PROTECTION SCHEME}

Since 1992, the reform of the CAP has addressed environmental concerns by 
promoting environmentally friendly farming. In particular, European Council Regulation 2078/92 promoted farmers to the roles of managers, stewards, and custodians of the rural environment, alongside that of producers of food commodity. For the first time, Member States were required to establish region-specific agrienvironmental schemes. Against this backdrop, in 1994 Ireland developed the REP Scheme with the stated objectives (DAF 2004) of:

- Establishing farming practices and production methods that reflect the increasing concern for conservation, landscape protection, and wider environmental problems;

- Protecting wildlife habitats and endangered species of flora and fauna;

- Producing quality food in an extensive and environmentally friendly manner.

The overall intention of the REP Scheme is to make support payments to farmers conditional on their implementing good and/or environment-friendly farming practice. The Scheme is about paying farmers to provide public goods in the form of environmental services (Hamell 2001), on the assumption that opportunity costs are being incurred in order to farm in an environmently friendly manner.

By the end of 2004, about a third of all farms and agricultural land in Ireland were involved in the Scheme, which is voluntary and available universally, rather than being restricted to specific areas of the country. However, in order to qualify, farmers must be farming at least three hectares of land and undertake to implement the Scheme on all of the holding and farming it according to an individual comprehensive agri-environmental plan for five years. Farmers in the Scheme must undertake a number of measures including controlling nitrogen use and stocking rates, controlling waste and effluent around the farmyard, and protecting water quality, hedgerows, stonewalls, and features of archaeological or historical importance.

\section{SURVEY DESIGN AND SAMPLING METHOD}

In order to estimate the WTP for various landscape improvements under the Scheme, a national survey based on choice experiments was developed. The results from one of these choice experiments are reported here and are sufficient to address the methodological issues at stake. The landscape attributes in question are the improvement of Mountain Land (ML), Stonewalls (S), Farmyard Tidiness (FT), and Cultural Heritage $(\mathrm{CH}){ }^{1}$

\section{Defining the Attributes}

The choice experiment exercise reported here involved several rounds of design and testing. It was carried out by a multidisciplinary team of landscape architects, policy specialists, and economists. This process began with a qualitative review of opinions from those involved in the design and implementation of the REP Scheme. Having identified the landscape improvements achieved by the policy, these were taken as relevant attributes for the choice experiment. Further qualitative research was carried out to refine the definitions of these attributes so that they could be used in the survey. This was achieved through a series of focus group discussions with members of the public. Pilot testing of the survey instrument was conducted in the field. This allowed the collection of additional information, which along with expert judgment and observations from the focus group discussions, was used to identify and refine the landscape attributes and their level of actual improvement. In the final version of the survey a total of eight important landscape attributes were identified. Evidence from the focus group discussions revealed that respondents had difficulty evaluating choice tasks with more than five attributes. To circumvent this, the survey contained two separate choice experi-

\footnotetext{
${ }^{1}$ The landscape attributes in the other choice experiment were the improvement in Wildlife Habitats, Rivers and Lakes, Hedgerows and Pastures. See Campbell (2006) for further details.
} 
ments, each comprised of four landscape attributes and a cost attribute. This paper, however, only reports on the findings of one of these, the interested reader is directed to Campbell (2006) and Campbell, Hutchinson, and Scarpa (2006) for further details on the entire study.

Three action levels were used to depict the effect of the Scheme on each rural landscape attribute. To minimize respondent confusion, the levels for each landscape attribute were denoted using the same labels: $A$ Lot Of Action, Some Action and No Action. While the $A$ Lot $O f$ Action and Some Action levels represented a high level and an intermediate level of improvement achievable within the Scheme respectively, the No Action level represented the unimproved or status-quo condition. Image manipulation software was used to prepare photo simulations representing the action levels of the landscape attributes. This involved the manipulation of a "control" photograph to depict standard outcomes of actions on the attribute in question. This method was used so that on the one hand the improvements in the attribute levels could be easily identified while holding other features of the landscape constant. On the other hand, the respondent would not perceive as ostensibly unrealistic the computer-generated landscape illustrations. For the Mountain Land attribute, diminished stocking densities were depicted, whereas the Stonewalls attribute was depicted to show the consequence that their state of maintenance and their removal has on the appearance of the countryside. Similarly, the Farmyard Tidiness attribute portrayed a farmyard at different levels of tidiness and the Cultural Heritage attribute showed the impact that different degrees of maintenance practices have on historical farm buildings and features. All images and accompanying wording were tested in the focus group discussions and pilot study to ensure a satisfactory understanding and scenario acceptance by respondents. $^{2}$

\footnotetext{
${ }^{2}$ All images and accompanying text and an example choice set are available to download from: http:// rep-scheme-valuation.tripod.com/ML_S_FT_CH.pdf.
}

The cost attribute was described as the expected annual cost of implementing the alternatives represented in the choice questions. This attribute was specified as the value that the respondent would personally have to pay per year, through their Income Tax and Value Added Tax contributions, to implement the alternative. These are realistic payment vehicles for EU-funded and government-funded agricultural policies. As discussed later, the experimental design was sequential and the survey was administered in two waves, plus a pilot. In the first wave of the survey five price levels were used $(€ 20, € 35, € 50, € 65, € 80$ ); while these were reduced to four in the second phase $(€ 15, € 20, € 40, € 50)$.

In the choice experiment, each respondent was asked to indicate their preferred alternative in each of a panel of choice tasks. Each choice task consisted of two experimentally designed alternatives, labeled "Option A" and "Option B," and a status-quo alternative, labeled "No Action," which portrayed all the landscape attributes at the No Action level with zero cost to the respondent.

\section{Sequential Experimental Design}

The experimental designs used in multiattribute, stated-preference can significantly influence the efficiency of WTP estimates (Lusk and Norwood 2005). This is a valuable approach to reduce survey cost by reducing the sample size needed to attain a given level of accuracy. To enhance estimation accuracy at a given sample size, one should employ an experimental design that maximizes an efficiency criterion. Further, bearing in mind that during the course of the survey gradually more information becomes available, one may increase the efficiency of the final estimates by adopting a sequential experimental design, rather than one design for the entire survey. Similar designs have been proposed in the early $1990 \mathrm{~s}$ in the referendum contingent valuation literature (Nyquist 1992; Kanninen 1993). In our case, the initial prior information was gathered from 
the pre-test and the first wave of interviews, which then informed the design of the second and final phase.

Given a set of attributes and attribute levels at which one desires to investigate responses, the problem of deriving an experimental design consists of finding an allocation of values in the matrix $X$ of data, so as to achieve an efficient identification of the parameter of interest during estimation given some knowledge on the relative magnitudes of the population $\beta$. A review of recent studies on experimental design for data to be analyzed with logit models revealed that the values of the levels in the matrix of attribute levels $X$ should be chosen so as to minimize some expected measure of variance, such as the $D p$ efficiency criterion, which is $\operatorname{det}\left\{I(\beta)^{-1}\right\}^{1 / k}$. A more informative Bayesian measure, the $D_{b}$-efficient criterion persuasively suggested by Sandor and Wedel (2001), was adopted here with the arrangement of values in X so as to minimize:

$$
\begin{aligned}
& E_{\beta}\left[\left\{\operatorname{det} I(\beta)^{-1}\right\}^{1 / k}\right]= \\
& \int_{\mathrm{R}^{k}}\left\{\operatorname{det} I(\beta)^{-1}\right\}^{1 / k} \pi(\beta) d \beta,
\end{aligned}
$$

where $I(\cdot)$ is the information matrix of the multinomial logit specification, $k$ is the number of attributes (nine in this case because of eight dummy variables and the cost variable). As a prior we used an informative multivariate normal distribution centered on $\beta$ and with variancecovariance matrix $\Omega$, both of which were derived initially from the response data collected in the pilot study, and subsequently updated at each phase by the pooled dataset from previous waves of sampling.

This is achieved in practice by simulating the value of this criterion by drawing from the assumed distribution of $\beta$, computing the value of the criterion for each draw, and then averaging it out. In practice, an adequate allocation of values is found by using heuristic algorithms, such as swapping and relabeling (Huber and Zwerina 1996) and cycling (Sándor and
Wedel 2001).

$\tilde{D}_{b}=\frac{1}{R} \sum_{r=1}^{R}\left\{\operatorname{det} I(\beta)^{-1}\right\}^{1 / k}$.

Starting from a conventional main effects fractional factorial in the first phase, a Bayesian design was employed in the second wave of sampling. However, not all values of the attributes were allocated in the design by the above approach. The numerical values of cost were assigned on the basis of realism and so as to balance the probabilities of choices across alternatives in the choice set (see Kanninen 2002). The mixing of the two approaches seems to be novel in this literature.

In estimation the use of two separate designs poses the question of whether or not the precision (or scale) parameter, which is inversely proportional to the error variance and typically standardized to 1 , is different for the logit specifications separately fitted to the first- and second-wave responses. After all, different designs imply different degrees of choice-complexity in the choice tasks faced by respondents (see among others, De Shazo and Fermo (2002) and Breffle and Rowe (2002)). However, fitting a scale parameter for one of the two subsamples does not improve the model significantly. So we conclude that there is no significant difference in variance of the error term which could have arisen from the difference in complexity of the choice task in one of the two waves. Of course, difference in complexity may manifest itself in forms other than changes in error variance. For example, extra complexity may induce respondent fatigue (respondent inefficiency) which may translate into irrational choices. For this reason, and following recommendations from previous studies, we introduced in our survey some basic tests for preference consistency.

\section{Preference Consistency Findings from Previous Studies}

Internal validity tests can be built into choice experiments' design to check respon- 
dents' "rationality." Rationality tests play an important role in choice experiments, as they can help identify respondents with inconsistent preferences. Respondents who choose irrationally or who show inconsistent patterns of response provide ambiguous information about their preferences. Including these respondents may unnecessarily increase the variance of resulting estimates and/or may lead to systematically biased point estimates. Sælensminde (2001, 2002), among others, found that there are significant differences in the valuation estimates between respondents who chose consistently and those who chose inconsistently. The costs of getting the valuation wrong are inherently greater in the case of multifunctional agriculture (Randall 2002). Hence, it is important that choice consistency be monitored in the experiment.

For example, Foster and Mourato (2002) do this in the context of a contingent ranking study of choice of bread types whose production process implied varying health (private) and birds (public) effects. They find that nearly half of the sample failed the test some time, but only 5\% did so systematically. Parameters estimates were found to be sensitive to the inclusion of choices including "irrational responses," but not to the extent of causing a significant effect on estimates of population WTP. They also found that "irrational" choices were not explained by obvious socio-economic differences (i.e., educational attainment), nor did their removal explain inconsistencies across ranks. Because their experiment mixed private and public goods, it is difficult to establish if rationality failures were linked to the nature of the good. More clear-cut results in this sense were provided by Johnson and Mathews (2001) who compared failures across two surveys, one concerning a public good (salmon preservation) and the second a private good (insulin treatments). They find failure rates to be higher in the public good survey across all "rationality" tests. Although Johnson and Mathews use a different way of testing from Foster and Mourato, they also found no significant effect of inconsistent responses on WTP estimates in their ordered probit analysis. Yet, the two studies are concordant in the findings that inconsistent results raise WTP estimates for both goods. We note that direct comparisons of these two studies to our data is prevented by the fact that neither of these two studies used the most common data format in choice-experiments to date, which tends to be based on preferred choices rather than ranked or rated ones. We found three studies examining the effect of inconsistencies in preferred choice data analysed using conditional logit models: one in health economics (San Miguel, Ryan, and Amaya-Amaya 2005) and the other two in transportation and environmental economics (Sælensminde 2001, 2002). All reported similar findings in terms of overall rate of theory-inconsistent responses, and of some link between degree of inconsistencies and education attainment of the respondent. Further, Sælensminde (2002) reports clear evidence of a positive effect of the number of inconsistent responses on estimated population means for WTP. However, none of these studies extends the analysis to employ panel specifications and to address heterogeneity of taste.

Discrepancies in population mean WTP estimates between fixed and random parameters logit specifications on the same data are well-documented in stated preference work (see, e.g., Layton 2000). Following Huber and Train (2001), we contend and show here that in addition to overcoming the well-known IIA restriction, one of the main advantages of panel mixed logit is the possibility to derive individual-specific WTP estimates.

In our study, in each sequence of choice tasks we included some additional choice tasks for this purpose, aside from those required by the experimental design. Specifically, two aspects of choice consistency were examined, monotonicity and stability. Monotonicity of responses was tested by including a choice task with a dominant alternative in the first choice experiment. In this choice question Option A was at least as good as Option B in terms of every 
attribute. It would obviously be inconsistent with the axioms of utility theory for any respondent to choose Option $\mathrm{B}$, that is, the dominated alternative. Preference stability was assessed by comparing responses to the same choice task included both at the beginning and end of the choice sequence. A respondent preferring a different alternative in the duplicate choice task would be classified as displaying unstable preferences. It is noteworthy that violation of neither of the two is conclusive proof of theoretically inconsistent or "irrational" behavior. For example, respondents can be violating stability of preference test as a consequence of learning their own preferences during the introspection exercise required by the choice tasks in the sequence. Similarly, violation of dominated choices may be due to the fact that respondents have constructed perceptions of missing attributes. Nevertheless, although these are possibilities, we take these violations as signals of an anomalous choice.

We note that the causes of irrational responses in choice experiments may be related to the features of the experimental design employed, especially when the choice set systematically includes a status quo alternative. Disentangling the causes of irrational response patterns is an issue beyond the scope of this paper, which nevertheless warrants further attention in applied research. The tradeoff between respondent efficiency and statistical efficiency of the experimental design is still relatively unexplored and poorly understood.

\section{Sampling Method}

In order to achieve a representative territorial spread, stratified-random sampling was used. The survey was firstly stratified according to 15 broad regions divided into five different community types (county boroughs; towns 10,000+; towns 5,000-10,000; towns 1,500-5,000; and rural less than 1,500) within the four standard areas of Ireland. This approach was to ensure that all data generated could be analyzed by the Nomenclature of Territo- rial Units for Statistics (NUTS) II and III regions, in addition to a range of urban and rural classifications. Within each of these broad regions, the appropriate number of primary sampling units, that is, Electoral Divisions (EDs), was chosen. In total, we selected 67 EDs. ${ }^{3}$

\section{MODEL SPECIFICATION}

\section{Bounding of Taste Intensities for \\ Landscape Improvements}

Although the experimental design was optimized for a multinomial logit model, in the phase of analysis there was evidence of unobserved preference heterogeneity and status-quo effects. While it was found that the representation of taste variation with finite mixing (i.e., latent class analysis as proposed by Boxall and Adamovicz 2002, Hensher and Greene 2003a, and Scarpa, Willis, and Acutt 2005) was not supported by the data, evidence for continuous mixing of taste intensities was strong. However, some commonly employed mixing distributions for utility parameters imply behaviorally inconsistent WTP values, due to the range of taste values over which the distribution spans. Ratios of normal and log-normal distributions are particularly problematic (Train and Weeks 2005) due to the presence of a share of respondents with the "wrong" sign in the former, and the presence of fat tails in the latter. This is of particular importance in our study which is concerned with landscape improvements on the status-quo, for which taste intensities are expected to be positive. ${ }^{4}$ After evaluating the results from various specifications and distributional assumptions, we followed Hensher and Greene (2003b) and opted for a bounded-triangular distribution in which the location parameter is con-

\footnotetext{
${ }^{3}$ For a general discussion on bounding the range of variation in random utility models see Train and Sonnier (2005) who propose a Bayesian estimation approach, for an application of bounding directly to the expenditure function see Train and Weeks (2005).

${ }^{4}$ See page 613 in Hensher, Rose, and Greene (2005) for a description of the triangular distribution in this context.
} 
strained to be equal to its scale. Such a constraint forces the distribution to be bounded over a given orthant, the sign of which is the same as the sign of the location parameter. In practice, for all random parameters associated with the various categories of rural landscape improvements we assumed $\beta \sim \tau(\theta)$, where $\theta$ is both the location and scale parameter of the triangular distribution $\tau(\cdot){ }^{4}$ This included cost, which was bounded to the negative orthant.

\section{Status-Quo Effects}

When the status-quo option is included in the set of alternatives, such inclusion can cause respondents to regard the status-quo alternative in a systematically different manner from the designed alternatives involving changes from the status-quo. This is because the status-quo is actually experienced, while the experimentally designed options are hypothetical. As a result, the utility from experimentally designed hypothetical alternatives are more correlated among themselves than with the utility associated with the status-quo.

This may be captured by a specification with additional errors accounting for this difference in correlation across utilities. Correlation is a consequence of the fact that experimental alternatives share this extra error component, which instead is absent from the utility of the status-quo alternative. Previous studies have found theoretical reasons for status-quo bias (Samuelson and Zeckhauser 1988; Haaijer 1999; Haaijer, Kamakura, and Wedel 2001), and choice experiment applications in environmental economics (see, e.g., Lehtonen et al. 2003; Kontoleon and Yabe 2003) found these effects to be significant. In a Monte Carlo study Scarpa, Ferrini, and Willis (2005) compare the performance of a number of standard random utility models addressing the status-quo effect. They find a flexible mixed logit error component model - which can induce a correlation structure across alternatives similar to that of a nested logit model - to be more robust to potential mis-specification than the latter. We hence employ such flexible error-component specification here. We assumed the following utility structure:

$$
\begin{aligned}
& U(c 1)=\tilde{\beta} x_{c 1}+\varepsilon+u_{c 1} \\
& U(c 2)=\tilde{\beta} x_{c 2}+\varepsilon+u_{c 2} \\
& U(s q)=\beta x_{s q}+u_{s q},
\end{aligned}
$$

where $\tilde{\beta}$ are random taste parameters for landscape improvements dummy variables and they are distributed triangular with the bounding restriction, $\varepsilon$ is a zero-mean normal error component inducing correlation amongst designed alternatives; $u$ is the usual unobserved utility component i.i.d. Gumbel, and $\beta_{s q}$ is a non-random statusquo specific constant.

The marginal probability of observing a sequence of choices $t(n)$ from individual $n$ is therefore

$$
\begin{aligned}
P(t(n)) & =\iint_{\tilde{\beta}} \prod_{\varepsilon}^{t(n)} \frac{\exp \left(\tilde{\beta} x_{t i}+\varepsilon_{i}\right)}{\sum_{j=c 1, c 2, s q} \exp \left(\tilde{\beta} x_{t j}+\varepsilon_{j}\right)} \\
& \times \varphi\left(\varepsilon \mid \sigma^{2}\right) \tau(\beta \mid \theta) d \varepsilon d \tilde{\beta},
\end{aligned}
$$

and the value of $\varepsilon_{j}$ is zero when $j=s q$.

Such probability is approximated in estimation by simulating the log-likelihood with Halton and shuffled Halton draws (Train 2003; Hess, Train, and Polack 2006).

\section{Individual-Specific Conditional Estimates of Landscape Values}

Rather than focusing on estimates of population mean WTP, we are interested in representing the sample variation of WTP values for landscape improvements, and in comparing the effects that removal of irrational respondents has on these distributions. Previous studies (Foster and Mourato 2002) based on conditional logit estimates made similar comparisons on ranking data by using the fact that the moment-based WTP estimates for attributes are non-linear transformation (ratios) 
of asymptotically normal estimates, and used parametric bootstrapping, such as the Krinsky and Robb procedure. Mixed logit panel estimation affords a more desirable avenue for comparison, where one can derive individual-specific estimates conditional on the observed individual choices $x^{n}$ and $y^{n}$ (Train 2003; Hensher and Greene 2003b; Greene, Hensher, and Rose 2005). This can be achieved by applying Bayes' theorem to derive the expected value of the ratio between the landscape attribute parameter estimate and the parameter estimate for the cost attribute:

$$
\begin{aligned}
E\left[\mathrm{WTP}^{n}\right] & =E\left[-\frac{\beta_{\text {att }}^{n}}{\beta_{\text {cost }}^{n}}\right] \\
& =\int_{\beta^{n}}-\frac{\beta_{\text {att }}^{n}}{\beta_{\text {cost }}^{n}} p\left(\beta^{n} \mid y^{n}, x^{n}\right) d \beta^{n} .
\end{aligned}
$$

Given two outcomes, A and B, Bayes' theorem relates $P(B \mid A)$ to the conditional probability of $P(B A)$ and the two marginal probabilities $P(A)$ and $P(B)$ as follows

$$
P(B \mid A)=\frac{P(A \mid B) P(B)}{P(A)} .
$$

So, substituting in

$$
\begin{aligned}
& E\left[W T P^{n}\right]=E\left[-\frac{\beta_{\text {att }}^{n}}{\beta_{\text {cost }}^{n}} \mid y^{n}, x^{n}\right] \\
& =\int_{\beta^{n}} \frac{-\beta_{\text {att }}^{n}}{\beta_{\text {cost }}^{n}} \frac{p\left(y^{n}, x^{n} \mid \beta^{n}\right) p\left(\beta^{n}\right)}{p\left(y^{n}, x^{n}\right)} d \beta^{n} \\
& =\int_{\beta^{n}} \frac{-\beta_{\text {att }}^{n}}{\beta_{\text {cost }}^{n}} \frac{p\left(y^{n}, x^{n} \mid \beta^{n}\right) p\left(\beta^{n}\right)}{\int_{\beta^{n}} p\left(y^{n}, x^{n} \mid \beta^{n}\right) p\left(\beta^{n}\right) d\left(\beta^{n}\right)} d \beta^{n} \\
& =\frac{\int_{\beta^{n}} \frac{-\beta_{\text {att }}^{n}}{\beta_{c o s t}^{n}} p\left(y^{n}, x^{n} \mid \beta^{n}\right) p\left(\beta^{n}\right) d\left(\beta^{n}\right)}{\int_{\beta^{n}} p\left(y^{n}, x^{n} \mid \beta^{n}\right) p\left(\beta^{n}\right) d\left(\beta^{n}\right)} .
\end{aligned}
$$

With knowledge of the $\beta$ estimates this can be approximated by simulation as follows

$$
\hat{E}\left[\mathrm{WTP}^{n}\right]=\frac{\frac{1}{R} \sum_{R} \frac{-\hat{\beta}_{\text {att }}^{n}}{\hat{\beta}_{\text {cost }, r}^{n}} L\left(\hat{\beta}_{r}^{n} \mid y^{n}, x^{n}\right)}{\frac{1}{R} \sum_{R} L\left(\hat{\beta}_{r}^{n} \mid y^{n}, x^{n}\right)},
$$

where $L$ is the logit probability conditional on the individual set of responses. In this way. the individual WTP estimates are obtained conditional on all the information from the choice experiment interview.

\section{RESULTS AND DISCUSSION}

In total, the choice experiment was administered by experienced interviewers to a representative sample of 402 respondents drawn from the Irish adult population in 2003-2004. With a further 120 potential respondents refusing to complete the interview, the overall response rate was $77 \%$. During the choice experiment, each respondent indicated their preferred alternative in a panel of repeated choice contexts, each choice consisting of two experimentally designed alternatives and a status-quo (No Action) alternative.

\section{Evaluation of the Efficiency of the Sequential Experimental Design}

One simple way to check whether estimation efficiency has increased by means of the sequential experimental design is by checking whether the scalar metric for the variance estimator $\operatorname{det}\left\{I(\beta)^{-1}\right\}^{1 / k}$ is smaller in the sample collected in the second phase. We find this value for the first phase sample estimates to be 1.45 that of the second, with nearly identical sample sizes.

Another way to evaluate the gains in efficiency obtained by using a sequential experimental design - such as the one employed here - is by comparing the estimated variance-covariance matrix of the logit model across the two sub-samples from each phase, with approximately the same sample size. The expectation is that the second sample should have a smaller variation of the estimates because its experimental design included more information. A smaller variance should translate into a difference matrix between first and second sample to be positive semi-definite, which is confirmed in our case. An increase in efficiency can also be detected by looking at the average increase of the absolute 
values of the asymptotic $z$-scores of the parameter estimates. In our case, the second sub-sample collected with the Bayesian design informed by the first sub-sample produced conditional logit estimates with an average increase of 2.22 .

On the other hand, this efficiency increase might come at a cost, that is, a decrease in respondent efficiency; for example, in terms of a significant difference in the numbers of respondents failing to pass the stability test across sample waves using different designs. A formal test of this hypothesis on the data fails to reject the null of no-difference across waves in the proportions of failures of this test. The monotonicity test is unaffected by differences in design because it was administered at the beginning of the panel.

We conclude that our sequential design delivered substantial efficiency gains in the context of the multinomial logit estimation, without reducing respondent efficiency in the way we can measured it. Moreover, it allowed greater flexibility and enabled the monetary attribute to be adjusted in response to the preliminary findings following each phase of the survey (Kanninen 2002).

\section{Preference Consistency}

Monotonicity of responses was tested by including a choice task with a dominant alternative in the first choice experiment. In this choice question Option A was at least as good as Option B in terms of every attribute. Of the 402 respondents, 38 (9\%) chose the No Action alternative in the choice task designed to diagnose monotonicity of preference. So, for $9 \%$ of the sample, we have no information on whether or not their preferences comply with monotonicity. Among the remaining 364 respondents, $86(21 \%$ of the sample) selected the dominated alternative (i.e., Option B). In the second choice experiment, preference stability was assessed over two independent choice tasks, one included at the beginning of the experiment and the other at the end. Evaluating trade-offs among non-market goods was likely to have been an unfamiliar task for most respondents and their initial preferences may not have been fully established and subject to change as introspection was exercised along the sequence of choices in the panel of each individual respondent. A higher proportion of respondents were found to have unstable preferences as the test identified that $111(28 \%)$ respondents chose a different alternative in the second choice task. Results from both consistency tests are summarized in Table 1 . Combining the results from both consistency tests revealed that 168 (42\%) respondents either selected the dominated alternative and/or had unstable preferences throughout the sequence. Therefore, the remaining $234(58 \%)$ respondents were identified as having consistent preferences. We note that similar fractions are reported in other studies (Sippel 1997; Foster and Mourato 2002; Johnson and Mathews 2001; San Miguel, Ryan, and AmayaAmaya 2005). Respondents who failed at least one test were classified as having inconsistent preferences. While this is a somewhat stringent criterion for classification, ${ }^{5}$ respondents who fail to detect a dominant alternative and/or have unstable preferences do not appear to satisfy the underlying axioms of rational choice. Responses to these test questions for rationality were outside the experimental design and were not used in the estimation of the structural models reported here.

\section{Comparison of Consistent and Inconsistent WTP Estimates}

The model of choice for the derivation of individual-specific welfare measures is the error component mixed logit model described in equation [6]. Table 2 reports the parameter estimates for three models. Model 1 pertains to the entire sample, Model 2 to the sample without the respondents who failed the monotonicity test,

\footnotetext{
${ }^{5}$ For example, one can argue that the stability test was failed by many because of fatigue accumulated by performing a cognitively demanding sequence of choicetasks. This is because the last choice task was designed to test for this form of stability.
} 
TABLE 1

Consistency Tests Results (Number of Respondents)

\begin{tabular}{llccc}
\hline \hline & & \multicolumn{2}{c}{ Monotonicity Test } & \\
\cline { 3 - 4 } & & Consistent & Inconsistent & Total \\
\hline Stability test & Consistent & 234 & 57 & $\mathbf{2 9 1}$ \\
Total & Inconsistent & 82 & 29 & $\mathbf{1 1 1}$ \\
\hline
\end{tabular}

while the estimates of Model 3 are obtained after eliminating from the sample those who failed both consistency tests.

Estimated coefficients for the landscape attributes are statistically significant across all models, and the relative dimensions conform to theoretical expectations of decreasing marginal utility of improvement, in fact, point estimates for "A lot of Action" are larger than those for "Some Action." A substantially improved average log-likelihood is obtained from the sample containing only consistent respondents.

WTP estimates based on the individualspecific welfare measures (equation [10]) (Hensher and Greene 2003b) are reported in Table 3. Again, results are presented for the three sub-samples to tease out the effect of various forms of axiomatic violations of rational preferences. With the exception for the parameter on some cultural heritage (CH_Some), the removal of inconsistent respondents resulted in a lowering of the WTP. This result is robust to other ways of computing welfare measures (e.g., using population moments) and confirms findings of previous stated preference studies. To further illustrate the effects of eliminating respondents with inconsistent or irrational responses in Figure 1 we contrast the plots of the kernel-smoothed distributions of the individual-specific WTP estimates conditional on observed choices for Farmyard Tidiness. ${ }^{6}$ It is apparent that as one moves from the estimates obtained from the whole sample (Model 1, continuous line) to those obtained from the sub-sample from which violators of monotonicity were removed

\footnotetext{
${ }^{6}$ Kernel plots for the other attributes are available at: http://rep-scheme-valuation.tripod.com/Distributions. pdf.
}

(Model 2, dashed-dotted line) and then to the sub-sample with only "rational" respondents (Model 3, dashed line), the WTP distributions shift markedly to the left.

To further highlight the features of the WTP distributions we report in Figure 2 the box-plots for these distributions. From the shapes of such plots it is evident that the implied monotonicity of the two levels of action on the landscape is adequately reflected in the magnitude of the implied WTP estimates and this property is robust to exclusion of irrational respondents. Nonoverlapping notches indicate rejection of the null of equal medians. It can be seen that respondents have much higher preference for "A lot of Action" in Mountain Land, but a low WTP for "Some Action," in fact as low as the least valued policy action: "Some Action" on Cultural Heritage. Another robust result illustrated by Figure 2, is that WTP variability is much higher for "A lot of Action" than for "Some Action," which is in keeping with prior expectations.

\section{CONCLUSIONS AND RECOMMENDATIONS}

This study attempted to take stock of all the main advances in the areas of multiattribute, stated-preference techniques to address the non-market valuation of rural landscape attributes through the REP Scheme in Ireland. In particular, following recent results in market research, we implemented a sequential experimental design with an informative Bayesian update to improve estimates efficiency; we addressed heterogeneity of the structural parameters of the random utility model using distributions that bounded the implied WTP 


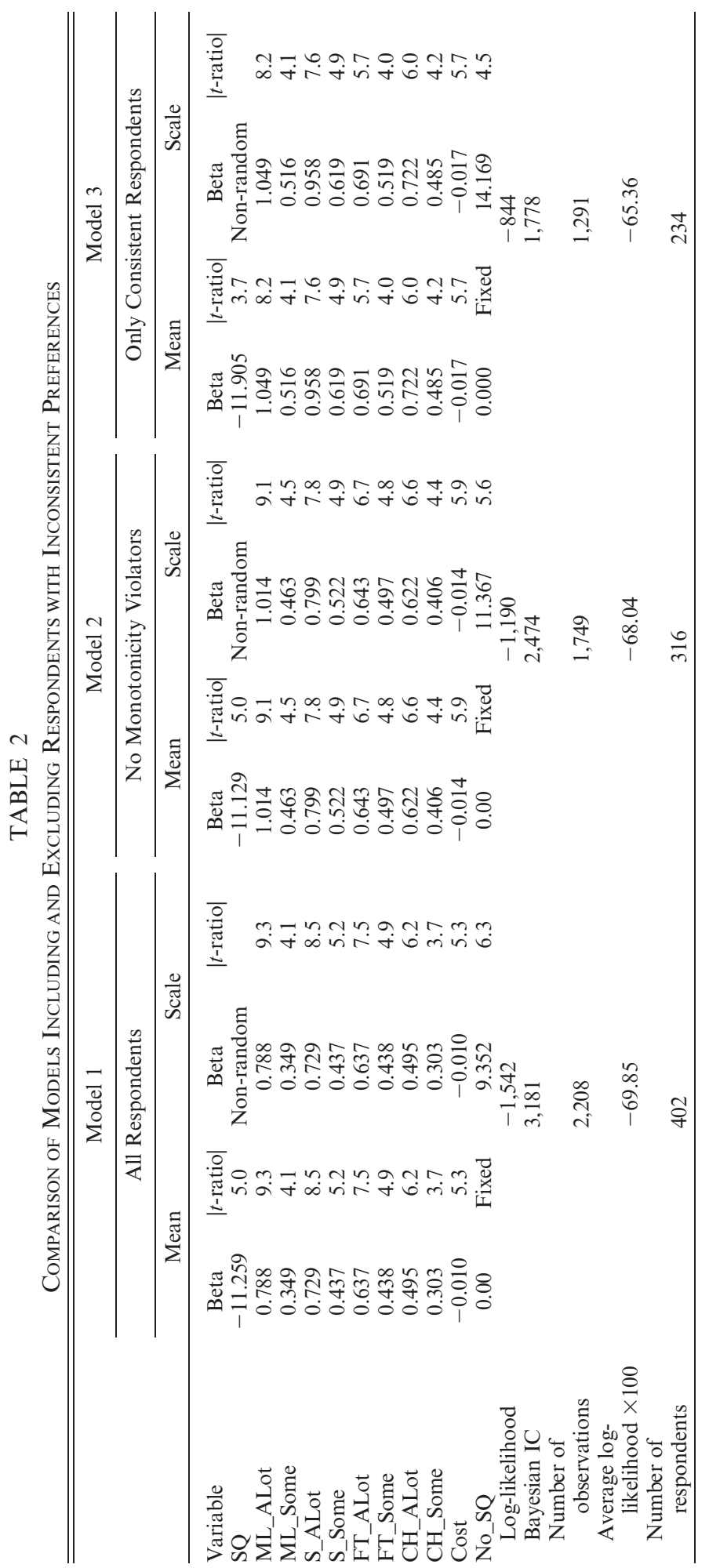


TABLE 3

Comparison of Individual WTP Descriptive Statistics InCluding and Excluding Respondents with Inconsistent Preferences ( $€$ Per Year)

\begin{tabular}{|c|c|c|c|c|c|c|}
\hline \multirow[b]{3}{*}{ Variable } & \multicolumn{2}{|c|}{ Model 1} & \multicolumn{2}{|c|}{ Model 2} & \multicolumn{2}{|c|}{ Model 3} \\
\hline & \multicolumn{2}{|c|}{ All Respondents } & \multicolumn{2}{|c|}{ Without Monotonicity } & \multicolumn{2}{|c|}{ Consistent Respondents } \\
\hline & Median & Mean & Median & Mean & Median & Mean \\
\hline ML_ALot & 104 & 104 & 95 & 102 & 91 & 93 \\
\hline ML_Some & 46 & 46 & 46 & 48 & 44 & 45 \\
\hline S_Ā & 96 & 97 & 80 & 81 & 80 & 84 \\
\hline S_Some & 56 & 58 & 51 & 52 & 53 & 55 \\
\hline FT_ALot & 83 & 84 & 64 & 67 & 60 & 60 \\
\hline FT_Some & 57 & 58 & 51 & 52 & 43 & 46 \\
\hline CH_ALot & 64 & 65 & 62 & 65 & 62 & 63 \\
\hline CH_Some & 39 & 40 & 40 & 40 & 41 & 42 \\
\hline
\end{tabular}

estimates for improvements to be positive. Then, to account for the fact that policy intervention takes the form of an improvement on the status-quo we used an error component specification to adjust to different patterns of correlations between utilities implying change and those referring to the status-quo. Finally, central to our investigation, was the identification of inconsistent and irrational respondents and the measure of the removal of their responses from the data on WTP estimates.

We can report several findings. First, the sequential Bayesian design improved the efficiency of the estimates across sampling waves and allowed greater flexibility in refining the levels of cost attribute, thereby providing multinomial logit estimates of the utility parameter which are more accurate by $10-30 \%$, depending on the parameter attribute. Considering that a shrinking of standard error is expected to take place proportionally to the square root of the sample size, this implies an increase in efficiency equivalent to increasing the sample size from 200 to a minimum of 242 , or a maximum of 338, depending on the parameter considered, that is, by $21 \%$
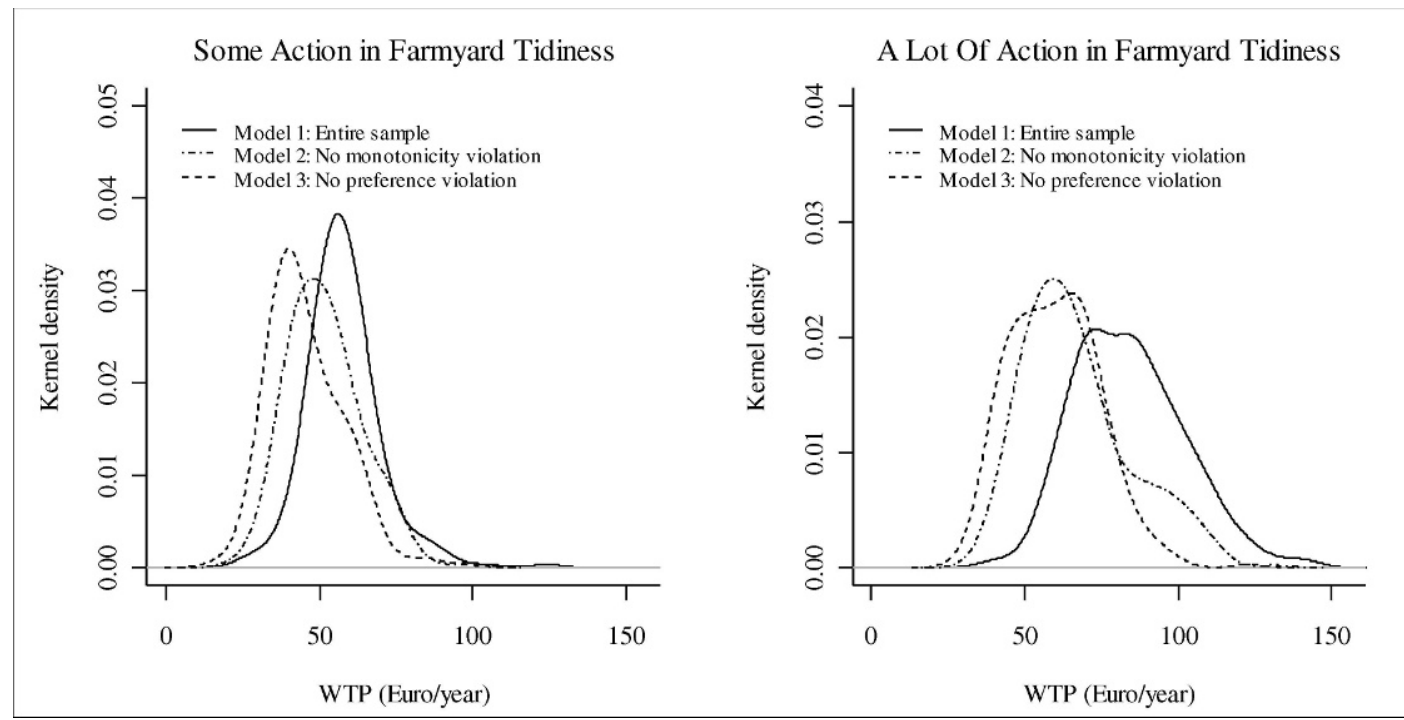

FIGURE 1

EfFect of Removal of “Irrational” Respondents on Distribution of WTP 


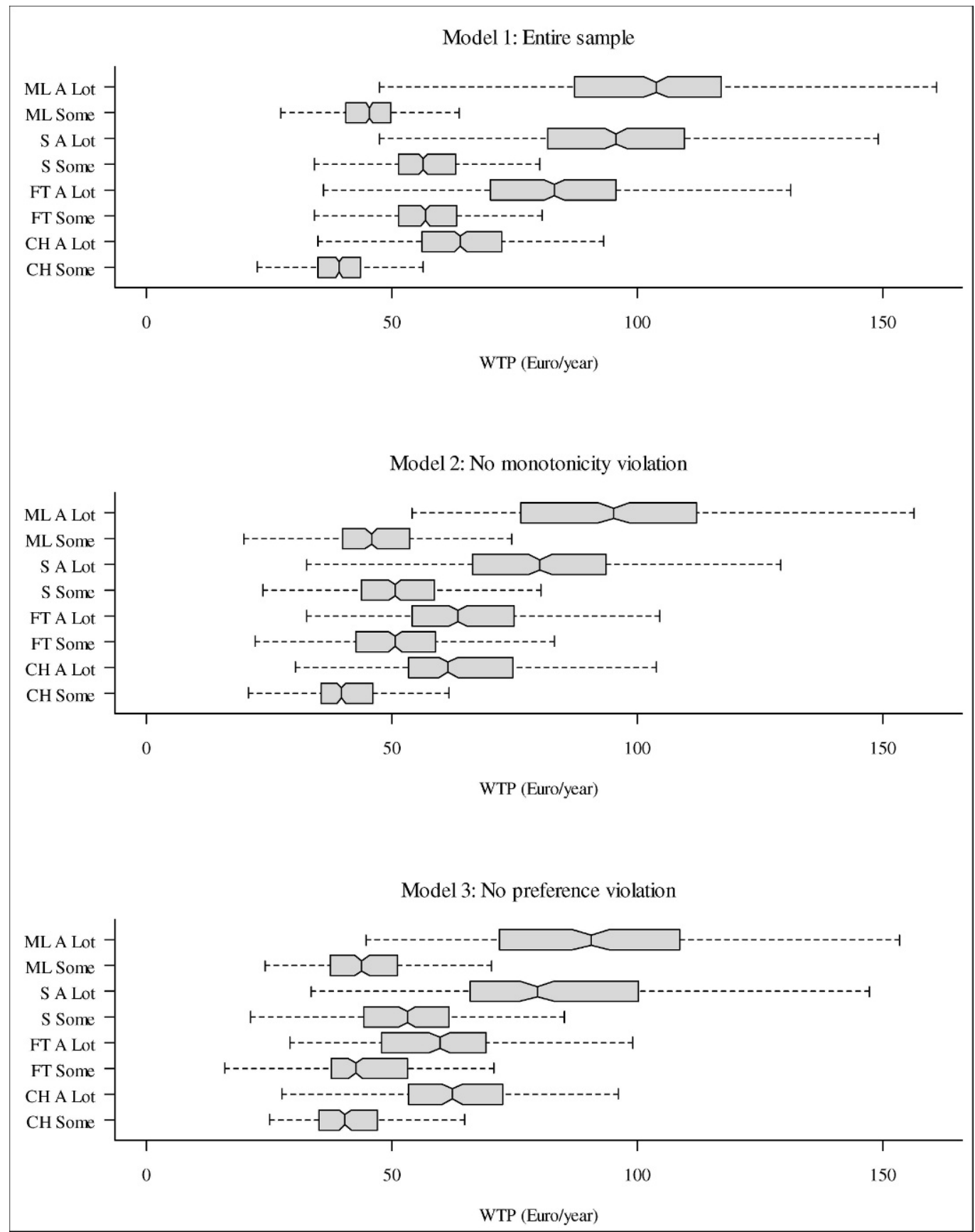

FIGURE 2

Box-Plots of Distributions of Individual-SPeCific WTP Estimates For LANDSCAPE ATtRIBUTES 
$68 \%$. Given that the average cost of an interview in this study was approximately $€ 58$, adopting a Bayesian design with updating was equivalent to a saving in the range of $€ 2436-€ 8004$ in the second wave of surveys. This increase in statistical efficiency was achieved without significant evidence of changes in respondent efficiency. Second, mean propensity to change from the status-quo is found to be substantial and so is correlation among choices implying landscape changes from the status-quo. This implies that the general public is strongly in favor of the improvements in the rural landscape typically brought about by the Scheme. Third, as in other studies, we find that, in general, the WTP estimates and the model fit are sensitive to the exclusion of irrational respondents. For example, excluding monotonicity violators improves the average model fit, as can be seen by comparing the values of the contributions to the log-likelihood per choice, and so does the further exclusion of respondents with unstable preferences across the sequence of responses. The subsample including only choices by rational respondents is associated with markedly lower WTP estimates (by 20\%-30\%) than those obtained from the entire sample. However, the implied preference ordering across policy actions is quite stable. Further, cardinal measures of WTP aside, we find the preference ordering to be the following. Highest WTP values are found for preserving Mountain Land through a high level of policy action, lowest for preserving Cultural Heritage, with maintaining Stonewalls and Farmyard Tidiness ranking in between. Finally, monotonicity in the intensity of improvements is respected as WTP for "A Lot of" landscape improvement is always higher than for "Some" improvement.

This article explored the sensitivity of estimates to omitting respondents with inconsistent preferences. Deciding whether or not to include inconsistent respondents is a judgment that should not be made on statistical criteria alone. Respondents who have inconsistent preferences do not appear to satisfy the underlying axioms of rational choice, and therefore the sensitivity of the WTP estimates to such decision should be investigated. The fact that a significant proportion of respondents evidently find it difficult to provide consistent responses, combined with the reported effect that the removal of such responses caused on WTP estimates suggests some caution in the policy use of WTP estimates when these issues are neglected in deriving non-market valuation estimates by means of the choice experiment methodology. The evidence presented in this article suggests quite clearly that choice experiment studies should incorporate procedures for identifying and screening out respondents with inconsistent preferences, and that WTP estimates should be evaluated for sensitivity to the inclusion and exclusion of such respondents. Finally, from the policy perspective, the overall results of this study seem to indicate that the benefits from improving rural landscape are of considerable magnitude.

\section{References}

Anderson, L. M. 1981. "Land Use Destinations Affect Perception of Scenic Beauty in Forest Landscapes.' Forest Science 27 (2): 392400.

Angileri, V., and A. Toccolini. 1993. "The Assessment of Visual Quality as a Tool for the Conservation of Rural Landscape Diversity." Landscape and Urban Planning 24 (1-4): 10512.

Atkinson, G., B. Day, and S. Mourato. 2004. “ 'Amenity' or 'Eyesore'? Negative Willingness to Pay for Options to Replace Electricity Transmission Towers." Applied Economics Letters 11 (4): 203-8.

Bastian, C. T., D. M. McLeod, M. J. Germino, W. A. Reiners, and B. J. Blasko. 2002. "Environmental Amenities and Agricultural Land Values: A Hedonic Model Using Geographic Information Systems Data." Ecological Economics 40 (3): 337-49.

Björklund, J., K. E. Limburg, and T. Rydberg. 1999. "Impact of Production Intensity on the Ability of the Agricultural Landscape to Generate Ecosystem Services: An Example From Sweden." Ecological Economics 29 (2): 269-91. 
Boxall, P. C., and W. L. Adamowicz. 2002. "Understanding Heterogeneous Preferences in Random Utility Models: A Latent Class Approach." Environmental and Resource Economics 23 (4): 421-46.

Boyle, M. A., and K. A. Kiel. 2001. "A Survey of House Price Hedonic Studies of the Impact of Environmental Externalities." Journal of Real Estate Literature 9 (2): 117-44.

Breffle, W. S., and R. D. Rowe. 2002. "Comparing Choice Question Formats for Evaluating Natural Resource Tradeoffs." Land Economics 78 (May): 298-314.

Brunstad, R. J., G. Ivar, and V. Erling. 1999. "Agricultural Production and the Optimal Level of Landscape Preservation." Land Economics 75 (Nov.): 538-46.

Bullock, C., and J. Kay. 1997. "Preservation and Change in the Upland Landscape: The Public Benefits of Grazing Management." Journal of Environmental Planning and Management 40 (3): 315-34.

Campbell, D. 2006. "Discrete Choice Experiments Applied to the Valuation of Rural Environmental Landscape Improvements." Ph.D. diss., Queen's University Belfast.

Campbell, D., W. G. Hutchinson, and R. Scarpa. 2006. "Using Discrete Choice Experiments to Derive Individual-specific WTP Estimates for Landscape Improvements Under Agri-environmental Schemes: Evidence from the Rural Environment Protection Scheme in Ireland." Working Paper No. 26:2006. Milan: Fondazione Eni Enrico Mattei.

Coiner, C., J. Wu, and S. Polasky. 2001. "Economic and Environmental Implications of Alternative Landscape Designs in the Walnut Creek Watershed of Iowa." Ecological Economics 38 (1): 119-39.

Cooper, J. C. 1997. "Combining Actual and Contingent Behavior Data to Model Farmer Adoption of Water Quality Protection Practices." Journal of Agricultural and Resource Economics 22 (1): 30-43.

Cooper, J. C., and R. Keim. 1996. "Incentive Payments to Encourage Farmer Adoption of Water Quality Protection Practices." American Journal of Agricultural Economics 78 (1): 54-64.

Cooper, J. C., and G. Signorello. Forthcoming. "Farmer Premiums for the Voluntary Adoption of Conservation Plans" Journal of Environmental Planning and Management.

Department of Agriculture and Food (DAF). 1999. Evaluation of the Rural Environment Protection Scheme. Dublin: Department of Agriculture and Food.
2004. Terms and Conditions of the Rural Environment Protection Scheme. Dublin: Department of Agriculture and Food.

DeShazo, J. R., and G. Fermo. 2002. "Designing Choice Sets for Stated Preference Methods: The Effects of Complexity on Choice Consistency." Journal of Environmental Economics and Management 44 (1): 123-43.

Elefthriadis, N., and I. Tsalikidis. 1990. "Coastal Pine Forest Landscapes: Modelling Scenic Beauty for Forest Management." Journal of Environmental Management 30 (1): 47-62.

Emerson, H. J., and D. A. Gillmor. 1999. "The Rural Environment Protection Scheme of the Republic of Ireland." Land Use Policy 16 (4): 235-45.

Ferrini, S., and R. Scarpa. 2007. "Designs with Apriori Information for Nonmarket Valuation with Choice-experiments: A Monte Carlo Study." Journal of Environmental Economics and Management 53 (3): 342-63.

Fleischer, A., and Y. Tsur. 2000. "Measuring the Recreational Value of Agricultural Landscape." European Review of Agricultural Economics 27 (3): 385-98.

Foster, V., and S. Mourato. 2002. "Testing for Consistency in Contingent Ranking Experiments." Journal of Environmental Economics and Management 44 (2): 309-28.

Geoghegan, J., L. A. Wainger, and N. E. Bockstael. 1997. "Spatial Landscape Indices in a Hedonic Framework: An Ecological Economics Analysis Using GIS.' Ecological Economics 23 (2): 251-64.

González, M., and C. J. León. 2003. 'Consumption Process and Multiple Valuation of Landscape Attributes." Ecological Economics 45 (2): 159-69.

Gorman, M., J. Mannion, J. Kinsella, and P. Bogue. 2001. "Connecting Environmental Management and Farm Household Livelihoods: The Rural Environment Protection Scheme in Ireland." Journal of Environmental Policy and Planning 3 (2): 137-47.

Greene, W. H., D. A. Hensher, and J. M. Rose. 2005. "Using Classical Simulation-Based Estimators to Estimate Individual WTP Values." In Applications of Simulation Methods in Environmental and Resource Economics, ed. R. Scarpa and A. Alberini. Dordrecht: Springer.

Haaijer, M. E. 1999. "Modeling Conjoint Choice Experiments with the Probit Model." Ph.D. diss., University of Groningen, The Netherlands.

Haaijer, M. E., W. A. Kamakura, and M. Wedel. 2001. "The No-Choice Alternative In Conjoint 
Choice." International Journal of Market Research 43 (1): 93-106.

Hamell, M. 2001. "Policy Aspects of the Agriculture-Environment Relationship." Tearmann: Irish Journal of Agri-Environmental Research 1 (1): $1-10$.

Hellerstein, D., C. Nickerson, J. Cooper, A. P. Feather, D. Gadsby, D. Mullarkey, A. Tegene, and C. Barnard. 2002. Farmland Protection: The Role of Public Preferences for Rural Communities. Washington, D.C.: USDA Economic Research Service.

Hensher, D. A., and W. H. Greene. 2003a. "A Latent Class Model for Discrete Choice Analysis: Contrasts with Mixed Logit." Transportation Research Part B 37 (8): 681-98.

- 2003b. "The Mixed Logit Model: The State of Practice." Transportation 30 (2): 133-76.

Hensher, D. A., J. M. Rose, and W. H. Greene. 2005. Applied Choice Analysis: A Primer. Cambridge, U.K.: Cambridge University Press.

Hess, S., K. Train, and J. W. Polack. 2006. "On the Use of Modified Latin Hypercube Sampling Method in the Estimation of a Mixed Logit Model for Vehicle Choice." Transportation Research B 40 (2): 147-63.

Huber, J., and K. Train. 2001. "On the Similarity of Classical and Bayesian Estimates of Individual Mean Partworths." Marketing Letters (12): 259-69.

Huber, J., and K. Zwerina. 1996. "The Importance of Utility Balance in Efficient Choice Designs." Journal of Marketing Research 33 (3): 307-17.

Johnson, F. R., and K. E. Mathews. 2001. "Sources and Effects of Utility-Theoretic Inconsistencies in Stated-preference Surveys." American Journal of Agricultural Economics 83 (5): 1328-33.

Kanninen, B. J. 1993. "Design of Sequential Experiments for CV Studies." Journal of Environmental Economics and Management 25 (1): $1-11$.

- 2002. "Optimal Design for Multinomial Choice Experiments." Journal of Marketing Research 39 (2): 214-27.

Kontoleon, A., and M. Yabe. 2003. "Assessing the Impacts of Alternative 'Opt-Out' Formats in Choice Experiment Studies: Consumer Preferences for Genetically Modified Content and Production Information in Food." Journal of Agricultural Policy and Resources 5 (1): 1-43.

Layton, D. F. 2000. "Random Coefficient Models for Stated Preference Surveys." Journal of Environmental Economics and Management 40 (1): 21-36.
Lehtonen, E., J. Kuuluvainen, E. Pouta, M. Rekola, and C. Z. Li. 2003. "Non-Market Benefits of Forest Conservation in Southern Finland." Environmental and Social Policy 6 (3): 195-204.

Lusk, J. L., and F. B. Norwood. 2005. "Effect of Experimental Design on Choice-Based Conjoint Valuation Estimates." American Journal of Agricultural Economics 87 (3): 771-85.

Mannion, J., M. Gorman, and J. Kinsella. 2001. "Connecting Farming, the Environment and Society: A Living Countryside Perspective." Tearmann: Irish Journal of Agri-Environmental Research 1 (1): 11-17.

Morrison, M., J. Bennett, R. Blamey, and J. Louviere. 2002. "Choice Modeling and Tests of Benefit Transfer." American Journal of Agricultural Economics 84 (1): 161-70.

Nyquist, H. 1992. "Optimal Designs of Discrete Response Experiments in Contingent Valuation Studies." Review of Economics and Statistics 74 (3): 559-63.

Pruckner, G. J. 1995. "Agricultural Landscape Cultivation in Austria: An Application of the CVM." European Review of Agricultural Economics 22 (2): 173-90.

Randall, A. 2002. "Valuing the Outputs of Multifunctional Agriculture." European Review of Agricultural Economics 29 (3): 289-307.

Sælensminde, K. 2001. "Inconsistent Choices in Stated Choice Data." Transportation 28 (3): 269-96.

. 2002. "The Impact of Choice Inconsistencies in Stated Choice Studies." Environmental and Resource Economics 23 (4): 403-20.

San Miguel, F., M. Ryan, and M. Amaya-Amaya. 2005. " 'Irrational' Stated Preferences: A Quantitative and Qualitative Investigation." Health Economics 14 (3): 307-22.

Samuelson, W., and R. Zeckhauser. 1988. "Statusquo Bias in Decision-making." Journal of Risk and Uncertainty 24 (1): 7-59.

Sándor, Z., and M. Wedel. 2001. "Designing Conjoint Choice Experiments Using Managers' Prior Beliefs." Journal of Marketing Research 38 (4): 430-44.

Scarpa, R., S. Ferrini, and K. G. Willis. 2005. "Performance of Error Component Models for Status-quo Effects in Choice Experiments." In Applications of Simulation Methods in Environmental and Resource Economics, ed. R. Scarpa and A. Alberini. Dordrecht: Springer.

Scarpa, R., K. G. Willis, and M. Acutt. 2005. "Individual-Specific Welfare Measures for Public Goods: A Latent Class Approach to Residential Customers of Yorkshire Water." In Econometrics Informing Natural Resource 
Management, ed. P. Koundouri. Cheltenham, U.K.: Edward Elgar.

Sippel, R. 1997. "An Experiment on the Pure Theory of Consumer's Behaviour." Economic Journal 107 (444): 1431-44.

Stewart, L., N. Hanley, and I. Simpson. 1997. "Economic Valuation Studies of the AgriEnvironment Schemes in the United Kingdom. Report to HM Treasury and MAFF." University of Stirling, United Kingdom.

Train, K. 2003. Discrete Choice Methods With Simulation. Cambridge, U.K.: Cambridge University Press.

Train, K., and G. Sonnier. 2005. "Mixed Logit with Bounded Distributions of Correlated Partworths."
In Applications of Simulation Methods in Environmental and Resource Economics, ed. R. Scarpa and A. Alberini. Dordrecht: Springer. Train, K., and M. Weeks. 2005. "Discrete Choice Models in Preference Space and Willing-to-Pay Space." In Applications of Simulation Methods in Environmental and Resource Economics, ed. R. Scarpa and A. Alberini. Dordrecht: Springer.

Willis, K. G., and G. D. Garrod. 1993. "Valuing Landscape: A Contingent Valuation Approach." Journal of Environmental Management 37 (1): 1-22.

1997. "Disamenity Externalities from Utility Networks." Utilities Policy 25 (1): 97-103. 